\title{
The Medical Effects of Seat-Belt Legislation in the United Kingdom: the collection of the data
}

\author{
H. R. M. HAYES \\ Child Accident Prevention Trust, London, England
}

\section{SUMMARY}

On 31 January 1983, it became compulsory for most drivers and front-seat passengers in vehicles with an unladen weight of less than 3 tons to wear seat-belts in the United Kingdom. This study was devised in order to provide definitive information on any changes in the injury patterns car and light goods vehicle occupants have suffered resulting from the law.

Originally it was expected that this aim would be achieved by collecting data from hospitals for a year before and a year after the introduction of the law. However, it proved impossible to collect data uniformly through the hospital system on all fatally injured casualties, and, in consequence, a parallel study of injuries sustained by fatalities was undertaken using coroners' records. The methodology of the hospital and fatal studies were very similar, excepting that the latter covered only two corresponding 6-month periods in 1982 and 1983.

\section{THE HOSPITAL STUDY: METHOD}

\section{The selection of the study hospitals}

Since data collection was to extend over 2 years and the number of relevant cases was relatively high (as shown by Table 1), it was obviously particularly important that the staff of those hospitals invited to participate were known to be interested in the subject and would remain committed to their involvement for the duration of the study. It is recognized that such a basis for selection may not be scientifically rigorous in that it may not generate a sample of accidents which can be regarded as nationally representative, but it is, nevertheless, a most important factor in maintaining the quality and supply of data.

It can be seen from Table 1 that the study hospitals were spread throughout the United Kingdom with three in Northern Ireland, two in Scotland, one in Wales and eight in England. Their catchment areas included both urban and rural roads and motorways.

\section{Case selection criteria}

The principal unit of data in this study was the casualty (as opposed to the vehicle or the accident). For a person to be included in the study, he or she had to meet all of the following conditions:

(1) he or she had to be involved in an accident involving a motor vehicle on a public highway between 1 February 1982 and 31 January 1984;

Correspondence: $\operatorname{Dr}$ H. R. M. Hayes, Child Accident Prevention Trust, 75 Portland Place, London, England 
Table 1 Number of cases from the participating hospitals

\begin{tabular}{lcc}
\hline Hospital & \multicolumn{2}{c}{ No of casualties } \\
\cline { 2 - 3 } & Year 1 & Year 2 \\
\hline Monklands Hospital, Airdrie & 247 & 220 \\
City Hospital, Belfast & 346 & 305 \\
Royal Victoria Hospital, Belfast & 216 & 209 \\
Ulster Hospital, Belfast & 605 & 568 \\
Royal Infirmary, Edinburgh & 661 & 474 \\
Royal Infirmary, Hull & 852 & 697 \\
General Infirmary, Leeds & 761 & 415 \\
Royal Hospital, Liverpool & 570 & 436 \\
University Hospital, Nottingham & 1105 & 1024 \\
Hope Hospital, Salford & 340 & 273 \\
General Hospital, Southampton & 984 & 839 \\
Taunton and East Somerset Hospital, Taunton & 630 & 600 \\
Pinderfields Hospital, Wakefield & 320 & 356 \\
War Memorial Hospital, Wrexham & 600 & 561 \\
\hline Total & 8237 & 6977 \\
\hline
\end{tabular}

(2) he or she had to be the occupant of a vehicle which was affected or would be affected from 31 January by the seat-belt-wearing law (basically this meant cars and vans up to about 3 tons unladen weight-similar vehicles registered before 1 January 1985-which do not require seat belts to be fitted were also included;

(3) he or she had to attend and be registered at the accident and emergency department of one of the study hospitals.

Patients who were transferred from other hospitals to the study hospitals for specialist treatment were excluded. Steps were taken during the course of the data-collection period to ensure that there were no variations in local case acceptance procedures at the hospitals which would influence this project, and no such changes were detected.

\section{The data collected}

Twenty-two data items were recorded for each person registered at a study hospital. Of these, 18 were normally entered on the main data-collection form at the hospital with the remainder completed by the coding clerk at the project headquarters. The data items collected were:

(a) hospital code (a single letter to indicate the relevant hospital);

(b) patient registration number (the hospital's identifying code for that patient, enabling the patient's record to be referred back to in the event of a query);

(c) patient age;

(d) patient sex;

(e) date of accident (day, month and year);

(f) time of accident;

(g) date of arrival at hospital;

(h) time of arrival at hospital;

(i) patient's seating position in car (driver, front passenger or rear passenger);

(j) injuries (entered in text at the hospital for coding later);

(k) condition on arrival (alive or dead);

(1) admission detail (whether or not patient was admitted to a ward);

(m) detail of death (whether patient died in hospital or not);

(n) date of discharge/death (recorded only for admitted patients);

(o) length of in-patient stay (recorded only for admitted patients); 
(p) seat-belt use;

(q) doctor's confidence in answer to seat-belt-use question;

(r) seat-belt use and injury status of other occupants of same vehicle (this was entered whenever. possible: there were considerable inter-hospital differences in its availability).

The four data items entered when the forms reached the project headquarters were:

(s) delay between accident and arrival at hospital;

(t) accident number;

(u) vehicle number (number assigned to vehicles within that accident);

(v) patient number (number assigned to patient within that vehicle).

\section{Data acquisition procedures}

Only two data items-seat belt usage and seating position-were to be recorded in this study over and above those normally collected under the standard procedures of most hospitals.

\section{Coding of the injuries}

The central two pages of the main data collection form were set out with sections for ten? anatomical regions and sub-regions. For each of these the type, precise location and severity of upto three injuries could be coded together with the total number of lesions in that region or subregion. The first code designated the type of injury, 'A' for abrasion, ' $F$ ' for fracture, 'W' forß wound etc. The second was an anatomical sub-division of the regions or sub-regions so that, in 3 the anatomical sub-regions for upper extremity, ' 1 ' stood for thumb, '2' for index finger, ' 3 ' for middle finger, etc. The full list of injury codes and anatomical sub-sections for each region or suß $\overrightarrow{-} \overrightarrow{0}$ region are given in the complete report (Rutherford et al., 1985). The third box in the line was ro the 1980 Abbreviated Injury Scale code (American Association for Automotive Medicine, 198बే:

When there were four to eight injuries, in a region or sub-region, the three most severe weres fully encoded as explained above, but the 'number of lesions' box indicated the total number of injuries, both classified and unclassified. In the very rare event that there were nine or more lesions in a region or sub-region the number was simply coded as nine.

\section{Data checking procedures}

There were two aspects of the data-checking procedures; some checks were carried out at the study hospitals by the author, and the forms were again checked during and after injury coding by the coding clerk.

A regular series of visits to all of the hospitals on the UK mainland was instituted for three reasons: to maintain the quality of the data, its constancy of flow and the general interest of the staff. Each of these hospitals was visited 16 times on average during the 2 years of data collection,, in other words approximately every 6 weeks. The Belfast hospitals were also visited a few times, 윽 but it was felt that their proximity and close contact with the project centre did not necessitate frequent visits.

During these routine visits, every completed form was scrutinized so as to minimize problemsñ for the coding clerk in Belfast. As far as possible, inter-hospital differences in injury descriptions were reduced particularly to allow uniform coding of their severity. Consistency between the patients' disposal, their length of in-patient stay and their injuries was checked, and anomalies $\omega$ were regularly questioned. Also, casualties from the same vehicle and accident were linked if this was not done by the hospital.

After a hospital had been visited and its forms checked, they were sent to Belfast. Here the injury information was coded and the other variables were rechecked. Any queries were referred 
back to the author to be resolved on his next visit to the appropriate hospital. A sample of the injury coding was checked by another of the investigators and the data put into the computer for analysis.

\section{Other aspects of the methodology}

Two points are worthy of note. Firstly, it should be mentioned that before the main phase of the data collection commenced, the experimental design and the forms had been piloted in all of the hospitals. This resulted in a modification of procedures with a consequential change in the paperwork being carried out.

Secondly, the further purposes of the regular visits should be explained. Initially, it was important to ensure that the personnel in each hospital had a clear understanding of what was required and that their systems were such that all relevant facts could be identified. Also, there was a need for local practices on such matters as the regular availability of data on casualties who were dead on arrival at the hospital to be discussed so that decisions could be taken on whether or not to include them in the sample. During the first visit a profile of the hospital's catchment area was also established.

\section{THE FATALS STUDY}

While the principles behind this part of the project were very similar to the hospital study, some practical differences were necessary. At the outset it was decided to collect a number of fatal cases which would be in approximately the correct proportion to the number of hospital cases, i.e. $1.5-2 \%$ in the first year of the study. For organizational reasons, data from 6 months of 1982 and the same period of 1983 were collected from eight coroners in England. The jurisdictions of these coroners did not coincide with the study hospitals and thus the two databases cannot be combined.

As with the hospital study, the coroners were not selected to provide a rigorously representative sample although they did cover urban and rural roads and motorways.

There were some differences in the data-collection methods for the studies. All of the data extraction was undertaken by the author, the coroners simply allowing access to their records. Further, some of the data coding was changed so the multiplicity of injuries to the fatally injured necessitated no restrictions being placed on the number of lesions in any body area which could be described in detail and also the cause of death was encoded. Information on seat-belt use and seating position was obtained from witness and police statements.

\section{COMMENTS ON METHODOLOGY}

Perhaps the facet of this study most open to criticism centres on the selection and hence nonrepresentativeness of the hospitals. For the prolonged collection of large amounts of data, the efficient participation of the hospitals can only be ensured either by providing additional staff (as in the Department of Trade and Industry's Home Accident Surveillance System); by only using hospitals with existing very detailed data collection systems (as will soon be available with the computer-based accident and emergency record (CAER) system), or by only involving hospitals the commitment of which was ensured at the outset. The automated linkage of police and health records could have provided many of the answers obtained in this project if it was available.

Limited funding and the absence of any computer-based system ruled out two options. The aspect of the procedures which went far in ensuring the continued commitment of the hospitals 
was the regular programme of frequent visits. The method should be regarded as a compromise between the ideal (additional staff in a representative group of hospitals) and the minimum (n programme of visits).

Similar comments can be applied to the fatals study. Here there would appear to be scope fo the automated collation of coroners' information which contain a wealth of data which would be relevant to this and similar studies.

Comparison of the results of the hospital study with those from the analysis of the datas collected by the police on all road accidents would have allowed some estimate of the्D representativeness of the catchment areas of the hospitals to have been established. To allow thi\$ comparison to be made, a data item which gave an indication of the nature of the accident location (for example, urban/rural/motorway, speed limit, road class, etc.), would have been needed: However, no such data item was collected. This was in part due to the limit on the number of questions which can reasonably be asked of an injured person in an accident and emergency? department. Clearly there was no such constraint on the data collected from coroners' records. 3

The accuracy of the answer to the question on the wearing of the seat belt, while very importanit if one is trying to comment on the effectiveness of seat-belts, is less significant if the primary comparison to be made is on the effectiveness of the legislation, i.e. a comparison of injuries seen in the years before and after the introduction of the law. Having said this, the clear impression waso that patients tended to give a truthful answer when asked about seat-belt use by the doctor as they_ had no particular reason to lie and they had confidence in the fact that the information given would remain confidential.

\section{POINTS RAISED IN OPEN DISCUSSION}

- Injuries were described in clinical terms then converted to an AIS number by one person Belfast.

- Police data about severity of accident are very subjective and variable, and this must b considered when 'data linkage' is discussed.

- ICD (International Classification of Diseases) was not used as it gives no indication of severity.

\section{REFERENCES}

American Association for Automotive Medicine (1980) The Abbreviated Injury Scale 1980 revision. Morton Grove: AAAM.

Rutherford W. H. et al. (1985). The Medical Effects of Seat-Belt Legislation in the United Kingdom. London? Her Majesty's Stationery Office. 